\title{
IS ONTIC STRUCTURAL REALISM A VIABLE FORM OF NATURALIZED METAPHYSICS?
}

\author{
Jack Ritchie \\ University of Cape Town
}

\begin{abstract}
RESUMO: Às vezes o naturalismo é apresentado como uma visão de mundo geral. Na maioria das vezes quando o naturalismo é assim apresentado, ele é identificado com o fisicalismo: a visão de que tudo é físico ou em algum sentido dependente do que é físico. Mas o fisicalismo enfrenta um problema muito sério e bastante conhecido, o dilema de Hempel. O problema pode ser colocado do seguinte modo: quando dizemos que tudo é físico, o que fazemos é utilizar o termo "físico" como é concebido pelo fisicalismo. Significamos o físico em termos da física atual? Se sim, então essa visão é provavelmente falsa. Esperamos que a física atual possa ser revisada assim como a ciência, a qual se desenvolve em caminhos desconhecidos, e, assim, algumas das reivindicações atualmente aceitas pelos físicos possam ser rejeitadas como falsas no futuro. Queremos com isso alguma física futuramente idealizada? Desde que não temos ideia do que essa física futuramente idealizada seja, não temos uma ideia real de qual é o conteúdo que o fisicalismo deve ter sob tal definição. Se nos dizem que física aqui significa apenas a disciplina que abarca todos os fatos dos quais todos os outros fatos são dependentes, então as reivindicações do fisicalismo são tautológicas.
\end{abstract}

\begin{abstract}
Sometimes naturalism is presented as a general world view. Most often when so presented naturalism is identified with physicalism: the view that everything is physical or in some sense dependent upon the physical. But physicalism faces a well known and very serious problem, Hempel's dilemma. The problem can be put like this: when we say everything is physical what do we mean by the physical in physicalism. Do we mean to define the physical interms of current physics? Well, then the view is almost certainly false. We expect current physics to be revised as science develops in unknown ways and so some of the claims currently accepted by physicists to be rejected as false in the future. Well, then do we mean some idealised future physics? Since we have no idea what that idealised future physics is, we have no real idea of what the content of physicalism is supposed to be on such definition. If we are told that physics here just means the discipline which captures all the facts which all other facts are dependent upon, then the claims of physicalism are tautological.
\end{abstract}




\section{Naturalised metaphysics and troubles caused by the history of science}

Sometimes naturalism is presented as a general world view. Most often when so presented naturalism is identified with physicalism: the view that everything is physical or in some sense dependent upon the physical. But physicalism faces a well known and very serious problem, Hempel's dilemma. The problem can be put like this: when we say everything is physical what do we mean by the physical in physicalism. Do we mean to define the physical interms of current physics? Well, then the view is almost certainly false. We expect current physics to be revised as science develops in unknown ways and so some of the claims currently accepted by physicists to be rejected as false in the future. Well, then do we mean some idealised future physics? Since we have no idea what that idealised future physics is, we have no real idea of what the content of physicalism is supposed to be on such definition. If we are told that physics here just means the discipline which captures all the facts which all other facts are dependent upon, then the claims of physicalism are tautological.

There is a vast literature on this problem but it is not my purpose to engage with that here. All we need to note is that Hempel's dilemma highlights a general problem, which a naturalist ought to be very sensitive, about combining naturalism with any very general world view. The history of science and physics teaches us that science is prone to revolutionary episodes. Basic ideas about how the world works are overthrown as physics develops. Once scientists thought, for example, there was absolute space, caloric and phlogisten but now we reject such ideas. So even modest reflection on science and its history ought to make us at the very least a little wary about drawing any confident conclusions about the fundamental furniture of the universe; and we would expect anyone calling themselves a naturalist to be at least that 


\section{$\underline{\text { Dossiê Naturalismo, Dissertatio - Volume Suplementar } 02}$ | UFPel [2015]}

reflective on science and its history since for a naturalist it is from science she hopes to build her philosophy.

Does this mean that that naturalized metaphysics is impossible. Not necessarily. Perhaps metaphysicians can learn something from scientific realists. Presented with the a history of science of past failure realists typically claim that a more nuanced reading of the history can show that where there appears to be discontinuity and error, there is in fact gradual accretion and progress. One metaphysical position which takes this approach is so called Ontic Strucutral Realism (OSR). In line with others that call themselves structuralist they believe that as science progresses we see structures retained from one theory to the next and so we have good reason to believe in those. To this epistemic thesis they add a radical metaphysical twist - all there is structure and, very importantly for this volume, a loud and confident proclamation that this is a radical form of naturalized metaphysics since its claims and arguments are drawn directly from science.

In the rest of the paper I explore this idea and it naturalist credentials. First I look at the argument which makes use of some odd aspects of contemporary physics to motivate the very radical thesis that there are no things. Then I consider structuralist responses to the problem of scientific revolutions before finally turning to consider whether the idea that structure is all there is makes any sense. My conclusions will be uniformly negative. The arguments for structuralism are poor and it is doubtful OSR makes sense.

\section{OSR as motivated by physics}

The argument for OSR from physics starts with some observations about the strangeness of quantum systems. Consider a system of two particles, illustrated below: 
Box A Box B
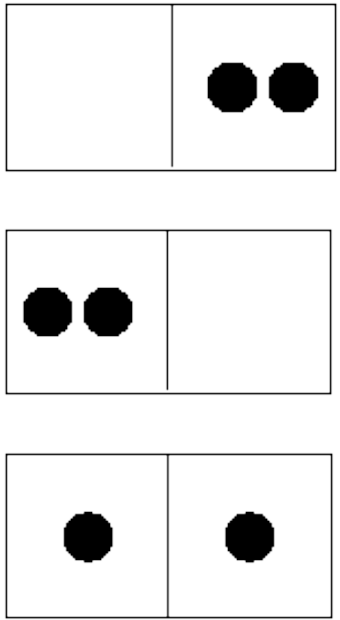

Classical physics says there are 4 possibilities here. Both particles can be in Box A, both in B, particle 1 in box $A$ and particle 2 in B and vice versa .

In quantum theory different statistics apply depending on what kind of particle is under consideration. In particle physics we divide particles into two kinds - - bosons and fermions. Bosons are particles like photons, and larger complex of particles like the hydrogen atom. They obey Bose-Einstein statistics. According to these statistics there are only three possible states these particles could be in. There is only one state corresponding to the bottom line ${ }^{1}$.

Fermions are particles like quarks and electrons. They obey FermiDirac statistics. There is only one possible state the fermions could be in according these statistics, the one represented by the bottom line. What is especially odd about all of this, whether the particles we are interested in are

${ }^{1}$ So if appropriate symmetries are in place so all states are equally probable, then classically we would expect the probability that the particles are in different boxes to be $1 / 2$ but in Bose-Einstein stats the probability would be $1 / 3$. 


\section{Dossiê Naturalismo, Dissertatio - Volume Suplementar 02 | UFPel [2015]}

fermions or bosons is that what we might think of as natural permutations of particles do not correspond to different physical states.

The fathers of quantum theory thought that this should lead to profound revision of our basic ontology. Here is how Hermann Weyl elegantly sums up the situation.

[T] he possibility that one of the identical twins Mike and Ike is in the quantum state E1 and the other in the quantum state E2 does not include two differentiable cases which are permuted on permuting Mike and Ike; it is impossible for either of these individuals to retain his identity so that one of them will always be able to say 'I'm Mike' and the other 'I'm Ike.' Even in principle one cannot demand an alibi of an electron! (Weyl 1931,)

Quantum particles they are argued could not be treated as individuals.

In the 1980s some philosophers of physics developed a different interpretation of the funny quantum statistics. They argued that quantum particles were individuals but whatever facts individuated the particles (some basic thisness or other metaphysical property) ${ }^{2}$ were not represented in the theory. The particles obeyed these funny stats not then because of their lack of individuality but simply because of nomological constraints. Not all the states that one would expect classically to be available to a particle where in fact possible states. Here is how Steven French sums up this view:

$[T]$ he implication of the different 'counting' in quantum statistics is not that the particles are non-individuals in some sense, but that there are different sets of states available to them, compared to the classical case. On this view, the particles can still be regarded as individuals however their individuality is to be understood metaphysically (French 1989).

This leads to what advocates of OSR call a version of metaphysical underdetermination. One theory, quantum mechanics, can have multiple

${ }^{2}$ The Bohm theory would be an example of this. Here the hidden variable is the definite particle position. 
interpretations. So even if one believed that the empirical success of that theory were good grounds to believe it, metaphysical underdetermination would imply that you would have no way of working out what the content of theory is that you ought to believe. The success of the theory is compatible with multiple, contradictory metaphysical interpretations.

This sounds like very bad news for realism of any kind but James Ladyman and others have argued that in fact cases of metaphysical underdetermination like this should motivate OSR.

In the case of individuality, it has been shown [...] that electrons may be interpreted either as individuals or as non-individuals. We need to recognize the failure of our best theories to determine even the most fundamental ontological characteristic of the purported entities they feature. It is an ersatz form of realism that recommends belief in the existence of entities that have such an ambiguous metaphysical status. What is required is a shift to a different ontological basis altogether, one for which questions of individuality simply do not arise (Ladyman 1998).

The argument is not elaborated much more than this in the publications of advocates of OSR but it seems to go as follows:

1. If we assume quantum objects, then our ontology is metaphysically underdetermined.

2. If our theories are metaphysically underdetermined, then we can't be realists about those theories since we do not know what we are being realists about.

3. If we adopt OSR, there is no metaphysical underdetermination.

Hence(?) if we want to be realists, our best bet is to be ontic structural realists

Let's just assume 1 is right for the reasons given by advocates of OSR. The argument even so seems very odd for it arrives at a metaphysical 


\section{Dossiê Naturalismo, Dissertatio - Volume Suplementar 02 | UFPel [2015]}

conclusion by apparently appeal to an epistemic problem. We don't know which interpretation of quantum theory is right so we should move to a third interpretation - OSR. But on the face of it OSR makes the problem of metpshucal underdetermination worse. Instead of just having two underdetermined rivals, it looks like we now have three. Particles as individuals, particles as non-individuals or no particles just structures. Why should we favour any one of these options over the others? ${ }^{3}$

Steven French (2014) has recently argued that OSR is not just another competitor interpretation but picks out the "common core" between the underdetermined rivals and that is why we should favour OSR over the two rival interpreations. But if OSR were the common core between these rival interpretations, then it would not deny anything asserted by the other theories. But it does. That there are objects. So this claim is implausible. It could be argued that what is the common core is the mathematical structure which is common to both interpretations but even if we grant that is so no metaphysical conclusion follows. Surely the most sensible attitude to adopt would be one of epistemic modesty. We should draw back from assenting to any claims that go beyond the structural. Such an attitude would be that of epistemic structural realism (ESR). ESR recommends that we believe in the structure of the theory but remain agnostic about all other claims. Hence in this case we ought to believe the fact about quantum systems contained in the group theoretic structures but be agnostic about whether there are particles and those particles are individuals. In short it seems to me that the favoured argument of metaphysical underdetermination offers no reasons to believe ontic structural realism but possibly some reason to accept ESR. With that I

${ }^{3}$ This point is made in Saatsi (2009) and Brading and Skiles (2012) 
mind I know turn to the arguments form the history of science which are meant to motivate both positions.

\section{OSR as motivated by the history of science}

As we noted above a fundamental difficulty for any metaphysical view with naturalistic pretensions is to offer some response to the problem of scientific revolutions. How can we get reliable information about how the world is from science given we expect our best scientific theories to be overthrown in the future? The general structure of any response to this problem will be to adopt a so called divide and conquer strategy. Scientific realists will typically argue that we have reasons to believe some parts of our theories but ought to be anti-realists about others. Structural realism is one such answer and it is best understood and motivated by looking at case study. ${ }^{4}$

\section{Fresnel and the ether}

The dominant view of the nature of light in the $19^{\text {th }}$ century was corpuscularian. Light consisted of rays formed of tiny particles. This theory could account for a wide range of optical phenomena including, reflection and refraction but it had difficulty in accounting for diffraction effects. Augustin Fresnel, showed that many of these diffraction phenomena (and indeed other features of light like polarization)could be accounted for if we adopted a new theory of light in which it was described as a transverse wave propagating through a luminiferous ether. Henri Poisson an advocate of the rival corpuscularian view, thought this led to a ridiculous result. If Fresnel's theory were right there should be a bright white spot in the centre of the shadow cast

\footnotetext{
${ }^{4}$ This is Worrall's(1989) example.
} 


\section{Dossiê Naturalismo, Dissertatio - Volume Suplementar 02 | UFPel [2015]}

by an opaque disc. Poisson took this result to be a reductio of Fresnel's theory. However, an experiment was performed to test Poisson's prediction and surprisingly the white spot was observed. Surely such an incredible result shows that light must be as Fresnel described it. Unfortunately, later physics does not support this view. Subsequent work by Maxwell and Einstein consigned the ether to history. If there's no ether, there's no vibrating in the ether and so there is nothing in the world like Fresnel's description of light.

Structural realists claim we can have the best of both worlds here. If we look more closely at Fresnel's theory we see that certain aspects of it are retained in later physical theories like Maxwell's. Specifically, the mathematical equations with which Fresnel described the relative intensities of reflected and refracted light reappear in Maxwell's theory unaltered. (See below.) Of course the referents of the key terms are different. For Fresnel the equations described a mechanical oscillation in a jelly-like stuff; for Maxwell and his successors they describe a displacement current in an electric field. But says the strucutural realist that shows us that what Fresnel got right was the structure of light as encoded in the mathematical equations; what he got wrong was its underlying nature. So we should be realist with respect to the structural claims of science and anti-realist about the claims that go beyond structure.

Fresnel's equations for the relative intensities of reflected and refracted light.

$$
\begin{aligned}
& \mathrm{R} / \mathrm{I}=\tan (\mathrm{i}-\mathrm{r}) / \tan (\mathrm{i}+\mathrm{r}) \\
& \mathrm{R}^{\prime} / \mathrm{I}^{\prime}=\sin (\mathrm{i}-\mathrm{r}) / \sin (\mathrm{i}+\mathrm{r}) \\
& \mathrm{X} / \mathrm{I}=(2 \sin r \cdot \cos \mathrm{i}) / \sin (\mathrm{i}+\mathrm{r}) \cos (\mathrm{i}-\mathrm{r}) \\
& \mathrm{X}^{\prime} / \mathrm{I}^{\prime}=2 \sin \mathrm{r} \cdot \operatorname{cosi} / \sin (\mathrm{i}+\mathrm{r})
\end{aligned}
$$


$I^{2}, R^{2}$ and $X^{2}$ represent the intensities of the incident, reflected and refracted beams respectively for the component of light polarised in the plane of incidence. $I^{2}, \mathrm{R}^{2}, X^{2}$ the same for the component of polarised light orthogonal to the plane of incidence. The angle of incidence of the beam is represented by $i$ and the angle of refraction by $r$.

\section{Generalising from the case}

What are we to make of this suggestion about how to respond to revolutionary episodes. One kind of problem which I will discuss in a bit more detail in the next section is something called the Newman problem which threatens the very coherence of structuralism. But before I look at that I want first to consider the general form of the structural realist response to see if even on its own terms it is plausible.

The structural realist recommends belief in the structure of scientific theories because it is claimed these structures are essential in explaining the success of scientific theories and because when we look at the history of science the mathematical structure is preserved (approximately) across theory change. I say approximately, of course, because the Fresnel case is somewhat atypical. It is not generally the case that exactly the same mathematical equations are retained from one theory to the next. But often enough the equations of a new theory can be recovered by some idealization ${ }^{5}$. For example, by setting the speed of light to infinity we can recover the Galilean transformations of Newtonian physics from the Lorentz transformations of special relativity.

So what we should expect when look through the history of science, if the structuralist is right, is that structure is in fact retained from one theory to the next and that retained structure is essential to the success of the past

\footnotetext{
${ }^{5}$ One might worry about what counts as an appropriate idealization. Not evry way of deriving a sset of equations from another could count for that would trivialize the claims of structural realism. But advocates strucutrual realisms have said very little about what should count as an appropriate idealization.
} 


\section{Dossiê Naturalismo, Dissertatio - Volume Suplementar 02 | UFPel [2015]}

scientific theory. I think this claim is not true and a simple example can show this.

Consider the shift that I alluded to above the move from Newtonian Mechanics to the special theory of relativity. Both of those theories are theories of space and time and as I explained some of the structuralist intuitions do indeed seem to apply to these theories. Consider another important structural continuity between these theories. Both theories describe space (or space-time) as flat. In other words, there is an important structural continuity at the level of global space-time structure. Moreover, it seems essential to both theories success that they represent space-time in this way. It is difficult to make sense, for example, of special relativity's success without reference to Minkowski space-time. Nevertheless( and I hope the lesson is obvious) even though structure here is retained form one theory to the next and even though that structure seems to play an essential role in explaining the success of the theory, we have for familiar reasons good reason to reject realism about the structure. The familiar reasons are of course further reflection on the future development of physics. General relativity supersedes both Newtonian mechanics and special relativity but, of course, it does not represent the structure of space-time as flat.

I suggest a simple example like this should be enough to undermine our confidence in the structuralist strategy. It just does not seem to be true in general that if a structure $e$ is retained from one theory to the next and that structure is part of what explains he success of the theory then that structure picks out something real. The history of science should make us as chary of structural realist claims as any other.

\section{OSR does it even make sense?}


So far I have argued that the arguments which are meant to motivate structural realism that appeal to metaphysical underdetermination in physics and theory change in science are no good. The first at best motivates an epistemological position rather than a metaphysical position and the second does not accurately reflect certain key developments in the history of physics. I want now to turn to a much more profound problem from structural realism. I will argue that not only are the arguments for structuralism no good but in fact its key claims make no sense.

First let me begin by considering the position discussed above, epistemic structural realism. What exactly does it mean to believe only in the structure of the theory? Well, the clearest way to make sense of the idea of a mathematical structure is in set theoretic terms. A set theoretic structure asserts that there exists a certain relation or relations defined extensionally which satisfy a domain of objects. But this claim cannot be what a scientific realist wants as a description of what is held true in a scientific theory for it is too easy to satisfy such a structure. Any set of objects provided it has the right cardinality can satisfy such a structure. This point was first made by W.H. Newman against a similar proposal from Bertrand Russell ${ }^{6}$. Newman puts it like this:

No important information about the aggregate A, except its cardinal number, is contained in the statement that there exists a system of relations, with A as a field, whose structure is an assigned one. For given any aggregate $\mathrm{A}$, a system of relations between its members can be found having any assigned structure compatible with the cardinal number A (Newman 1928, p.140. Italics in the original).

\footnotetext{
${ }^{6}$ Russell (1927) is taken by advocates of SR as an early version the structuralist project although its motivations are quite different from those of Worrall's paper. See Stathis Psillos (2001) for what he calls the upward and downward paths to SR.
} 


\section{Dossiê Naturalismo, Dissertatio - Volume Suplementar 02 | UFPel [2015]}

To know then the structure is to know no more the cardinality of your domain. A scientific realism based on this claim is empty.

Many people (including me) think this objection fatally undermines epistemic structural realism but advocates of the position we are interested in discussing here, OSR, have a very neat solution to this problem. Since according to OSR there are no objects, it makes no sense to talk of the same structure satisfying different domains of objects; all there is is the structure itself. This neat solution though quickly gives rise to an equally serious problem for advocates of OSR.

Advocates of OSR like Ladyman and Ross(2007) think the fundamental structures which exist in the world are mathematical in nature That's why they say things like this:

\footnotetext{
if one were asked to present the ontology of the world according to .... [general relativity] one would present the apparatus of differential geometry and the field equations and then go on to explain the topology and other characteristic of the particular model... of these equations... There is nothing more to be said (p. 159)
}

But now we have to answer the obvious question how is this physical structure different from the mathematical structure which we would normally think of as representation of it. What in short makes something a physical structure as opposed to a mathematical structure? The problem for a structuralist metaphysics is that whatever they appeal to differentiate physical from mathematical structure they will face the following dilemma: Let us call the fact which differentiates physical from non-physical structure, $\mathrm{X}$. Is X a structural fact? If not then there is at least one non-structural fact and so OSR is false. If it structural, then we have just pushed our question back. How now 
are we meant to distinguish this enriched structure from an enriched mathematical structure which could represent it?

Both Ladyman and Ross (Ladyman, Ross and Kincaid 2013, ch.6) in recent talks and papers have tried to address this issue. Ross has claimed the world is the totality of non-redundant statistics and that this avoids the above dilemma since there is "no such thing as purely formal statistics". But this is just rhetoric. Statistics can indeed be worked out purely formally (that is what they study in departments of pure statistics) what is needed is some reason to say a particular model is an adequate representation of some facts; and that requires a way of differentiating the statistical model from the represented facts. No appeal to non-redundant statistics does that. This is essentially a repacking of the original problem.

Ladyman (2011) in a discussion with van Fraassen offers an alternative route. He has suggested that we might adopt "intensionalism about the relevant relational structure" or "that there is in the world some causal or nomological structure that is represented by logical and mathematical relationships in our theoretical thought"(421). The suggestions here are very vague and programmatic to say the least but I will content myself with two observations. First, this appears to admit the need for non-structural elements in order for there to be a viable position but secondly and this takes us back to where we began, it seems very likely that in order to make sense of and develop these ideas further Ladyman will have to appeal to a priori metaphysical theorising. Accounts of intensional properties or causal structure will not be found to be read off from our science and so OSRists claims to be doing an entirely novel naturalised form of metaphysical theorising will be

7 Disappointingly, despite being aware of the question, Ladyman and Ross (2006) in their book "refuse to answer it" (158). But the question is compulsory. Without an answer to it, it is impossible to make sense of the claims of OSR. 


\section{Dossiê Naturalismo, Dissertatio - Volume Suplementar 02 | UFPel [2015]}

undermined. They, like more orthodox metaphysicians, will be left to appeal to intuitions and non-empirical data to support their programme.

\section{Conclusion}

OSR is a bold and ambitious metaphysical programme which promises to offer a new and interesting way to do metaphysics by engaging both with physical theory and its historical development. Anyone who thinks of themselves as a naturalist will find much to celebrate in the work of Ladyman, French, Ross and other advocates of OSR. Unfortunately, the arguments offered in favour of OSR are disappointing. Naturalised metaphysicians have yet to offer us a world view which can be said to be truly naturalistic while acknowledging our epistemic frailty in the face of scientific revolutions. The search must go on.

\section{REFERENCES}

BRADING, K. \& SKILES. "A Underdetermination as a Path to Ontic Structural Realism" in Lanry and Rickles (eds.) Structural Realism The Western Ontario Series in Philosophy of Science Volume 77, 2012, pp 99-115.

FRENCH, S. "Identity and Individuality in Classical and Quantum Physics", Australasian Journal of Philosophy, 67, 1989, p. 432-446.

FRENCH, S. The structure of the world Oxford: Oxford University Press. 2014.

LADYMAN, J. What is structural realism? Studies in the History and Philosophy of Science 29, 1998, pp. 409-24.

LADYMAN, J. "Scientific representation: A long journey from pragmatic to pragmatics” Metascience 20, 2011, pp. 417-442. 
LADYMAN, J. \& ROSS, D. Everything Must Go: Metaphysics Naturalized Oxford: Oxford University Press, 2007

LADYMAN, J. ROSS, D. and Kincaid, H. (eds.), Scientific Metaphysics, Oxford University Press, 2013.

SAATSI, J. "Whence Ontic structural realism?” EPS A 2007 Proceedings, 2009.

WORRALL, J. Structural realism: the best of both worlds? Dialectica 43, 1989, pp. 99-124

WEYL, H. The Theory of Groups and Quantum Mechanics, London: Methuen and Co., English trans., 2nd edition, 1931. 